\title{
Link between EMIC waves in a plasmaspheric plume and a detached sub-auroral proton arc with observations of Cluster and IMAGE satellites
}

\author{
Zhigang Yuan, ${ }^{1}$ Xiaohua Deng, ${ }^{1}$ Xi Lin, ${ }^{1}$ Ye Pang, ${ }^{1}$ Meng Zhou, ${ }^{1}$ P. M. E. Décréau, ${ }^{2}$ \\ J. G. Trotignon, ${ }^{2}$ E. Lucek, ${ }^{3}$ H. U. Frey, ${ }^{4}$ and Jingfang Wang ${ }^{1}$ \\ Received 28 January 2010; accepted 3 March 2010; published 13 April 2010.
}

[1] In this paper, we report observations from a Cluster satellite showing that ULF wave occurred in the outer boundary of a plasmaspheric plume on September 4, 2005. The band of observed ULF waves is between the $\mathrm{He}^{+}$ion gyrofrequency and $\mathrm{O}^{+}$ion gyrofrequency at the equatorial plane, implying that those ULF waves can be identified as EMIC waves generated by ring current ions in the equatorial plane and strongly affected by rich cold $\mathrm{He}^{+}$ions in plasmaspheric plumes. During the interval of observed EMIC waves, the footprint of Cluster SC3 lies in a subauroral proton arc observed by the IMAGE FUV instrument, demonstrating that the subauroral proton arc was caused by energetic ring current protons scattered into the loss cone under the Ring Current (RC)-EMIC interaction in the plasmaspheric plume. Therefore, the paper provides a direct proof that EMIC waves can be generated in the plasmaspheric plume and scatter RC ions to cause subauroral proton arcs. Citation: Yuan, Z., X. Deng, X. Lin, Y. Pang, M. Zhou, P. M. E. Décréau, J. G. Trotignon, E. Lucek, H. U. Frey, and J. Wang (2010), Link between EMIC waves in a plasmaspheric plume and a detached sub-auroral proton arc with observations of Cluster and IMAGE satellites, Geophys. Res. Lett., 37, L07108, doi:10.1029/2010GL042711.

\section{Introduction}

[2] Satellite observations and computer simulations have shown that electromagnetic ion cyclotron (EMIC) waves can be generated by a resonant interaction with ring current (RC) ions [e.g., Horne and Thorne, 1993; Fraser et al., 2005; Gamayunov and Khazanov, 2008]. During disturbed periods, the sunward transport of ring current ions produces anisotropic $\left(\mathrm{T}_{\perp}>\mathrm{T}_{/ /}\right)$particle distributions [Sibeck et al., 1987]. In addition, the ion anisotropy can also be increased through the solar wind compression of the magnetosphere [Anderson and Hamilton, 1993]. Those energetic and anisotropic ring current protons are considered to provide the major source of free energy driving this instability and causing the amplification of EMIC waves [Anderson et al., 1992a; Erlandson and Ukhorskiy, 2001; Engebretson et al., 2007]. Since the instability threshold is so low that

\footnotetext{
${ }^{1}$ School of Electronic Information, Wuhan University, Wuhan, China.

${ }^{2}$ Laboratoire de Physique et Chimie de l'Environnement, University of Orléans, CNRS, Orléans, France.

${ }^{3}$ Blackett Laboratory, Imperial College London, London, UK.

${ }^{4}$ Space Sciences Laboratory, University of California, Berkeley, California, USA.

Copyright 2010 by the American Geophysical Union. 0094-8276/10/2010GL042711
}

EMIC waves are easily generated in the presence of cold dense ions [Gary et al., 1995], strong enhancements of the EMIC wave power occur at the plasmapause [Anderson et al., 1992a; Fraser and Nguyen, 2001; Masson et al., 2009]. In fact, since cold $\mathrm{He}^{+}$ions have a strong influence on the proton cyclotron electromagnetic instability [Gomberoff and Cuperman, 1982; Kozyra et al., 1984], most observed EMIC waves in the frequency range of Pc1-2 have spectra whose characteristic frequencies are organized in the vicinity of the $\mathrm{He}^{+}$gyrofrequency at the equatorial plane [Young et al., 1981; Sakaguchi et al., 2008].

[3] Observations of the CRRES spacecraft have presented that the occurrence of EMIC waves predominates in the afternoon [Fraser and Nguyen, 2001]. Due to the RC-EMIC interaction, ring current protons can be scattered into the loss cone and cause subauroral arcs [Burch et al., 2002; Fuselier et al., 2004; Jordanova et al., 2007; Yahnina et al., 2008]. The tendency for subauroral arcs is demonstrated to be located in the mid-afternoon sector during disturbed periods, where plasmaspheric plumes can extend sunward from the main plasmasphere [Immel et al., 2002; Burch et al., 2002; Darrouzet et al., 2009]. Therefore, anisotropic yet stable energetic proton distributions drifting westward from dusk are expected to become more unstable when encountering cold dense ions within a plasmaspheric plume. As a result, EMIC waves would be further amplified and scatter ring current protons into the loss cone and cause subauroral arcs. With observations of the IMAGE satellite, the link of a plasmaspheric plume and subauroral arcs implies that EMIC waves may be preferentially generated within the plume [Spasojević et al., 2004]. However, in their paper, the direct observation of EMIC waves was not presented in the plasmaspheric plume. In addition, a direct link between EMIC wave observations and ion precipitation into an isolated proton aurora was also presented [Miyoshi et al., 2008]. In their paper, the isolated proton aurora is associated with EMIC waves not in the plasmaspheric plume but at the plasmaspause.

[4] In this paper, we present results of a case study on September 4, 2005 during which a direct link has been found between EMIC waves in a plasmaspheric plume observed by the Cluster satellite and a subauroral proton arc observed by the IMAGE satellite. In section 2, we present the observation of the Cluster satellite on September 4, 2005. In section 3, these results are discussed and compared with observations of the IMAGE satellite. Finally, a summary is given.

\section{Observations of Cluster Satellite}

[5] The Cluster WHISPER instrument allows one to identify the electron plasma frequency in the range of 


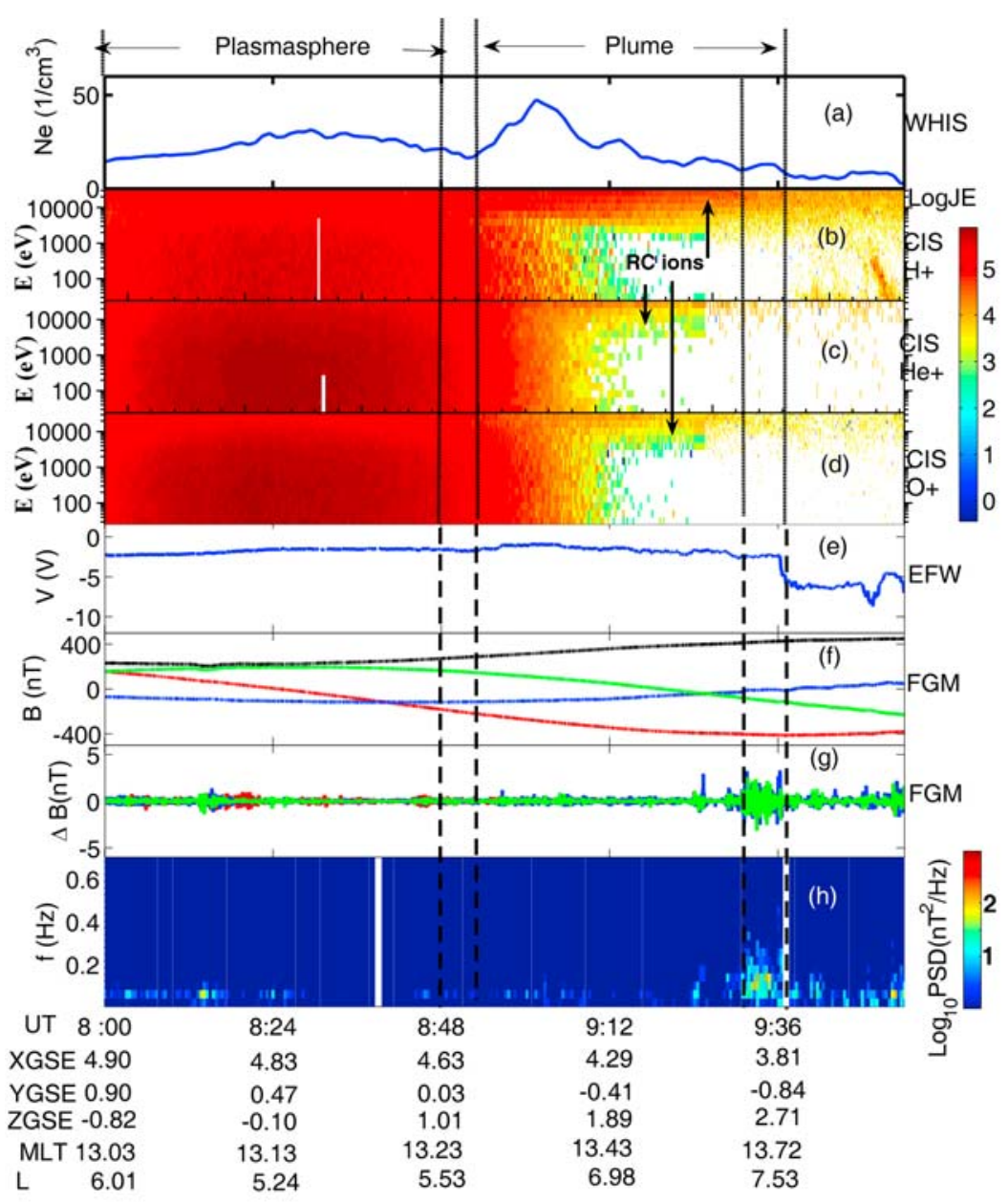

Figure 1. Overview of data from Cluster SC3 in the GSE coordinates and between 08:00 and 09:50 UT on September 4, 2005. (a) Electron density derived from the electron plasma frequency detected by the WHISPER instrument. (b-d) CODIF omnidirectional energy-time spectrograms in particle flux units separately for $\mathrm{H}^{+}, \mathrm{He}^{+}$and $\mathrm{O}^{+}$ions. (e) Negative of the spacecraft potential measured by the EFW experiment. (f) Averaged magnetic fields and (g) disturbed magnetic fields measured by FGM with a time resolution of $0.1 \mathrm{~s}$ derived by using a $25.6 \mathrm{~s}$ running window. The $x, y, z$ component in the GSE coordinates and total magnetic field are denoted by blue, red, green and black solid lines, respectively. (h) Power spectrum density (PSD) of the $z$ component of disturbed magnetic fields.

2-80 kHz [Décréau et al., 2001]. These data can be used to analyze the density structure of plasmaspheric plumes when corresponding plasma frequencies lie in this range [Darrouzet et al., 2006]. Electron densities presented in this paper are provided by the Cluster WHISPER instrument at a time resolution of about $2 \mathrm{~s}$ [Décréau et al., 2001]. The magnetic field is obtained from the Fluxgate Magnetometer (FGM) with a $22 \mathrm{~Hz}$ sampling frequency [Balogh et al., 2001]. The Composition and Distribution Function Analyzer (CODIF) of the Cluster Ion Spectrometry (CIS) instrument provides the three-dimensional ion distribution functions (about 5-40 keV/q) with one spacecraft spin (4 s) time resolution [Rème et al., 2001]. Furthermore, the massresolving spectrometer CODIF provides the ionic composition of the plasma separately for the major magnetospheric species $\left(\mathrm{H}^{+}, \mathrm{He}^{++}, \mathrm{He}^{+}\right.$, and $\left.\mathrm{O}^{+}\right)$, from the thermal energy to about $40 \mathrm{keV} / \mathrm{q}$, covering thus a substantial part of the ring current energy range [Williams, 1987]. The spacecraft potential data come from the Electric Field and Wave (EFW) experiment on board Cluster [Gustafsson et al., 2001].
[6] A plume crossing, identified in density versus time profiles at Cluster perigee, can be characterized by means of several parameters [Darrouzet et al., 2008]. A plume is identified as a significant and localized density increase followed by a density decrease from the background value, in a region adjacent to the main plasmasphere. The $L$-width of the structure, where $L$ is the McIlwain parameter [McIlwain, 1961], should be enough for the structure to be considered as a plasmaspheric plume. Darrouzet et al. [2008] fixed the minimum value of $L$ width to $0.2 \mathrm{Re}$. To calculate the $L$-shell value of the McIlwain parameter at Cluster's location, we use a model that combines the internal magnetic field model IGRF2000 and the external magnetic field model TSK-05 depending on the solar wind pressure, the Dst index, and the interplanetary magnetic field (IMF) $Y$ and $Z$ components [Tsyganenko and Sitnov, 2005]. In addition, we projected Cluster trajectories along the magnetic field of this model onto the equatorial plane in order to derive the $\mathrm{He}^{+}$gyrofrequency $\left(f_{\mathrm{He}+\mathrm{eq}}\right)$ at the equatorial plane. 


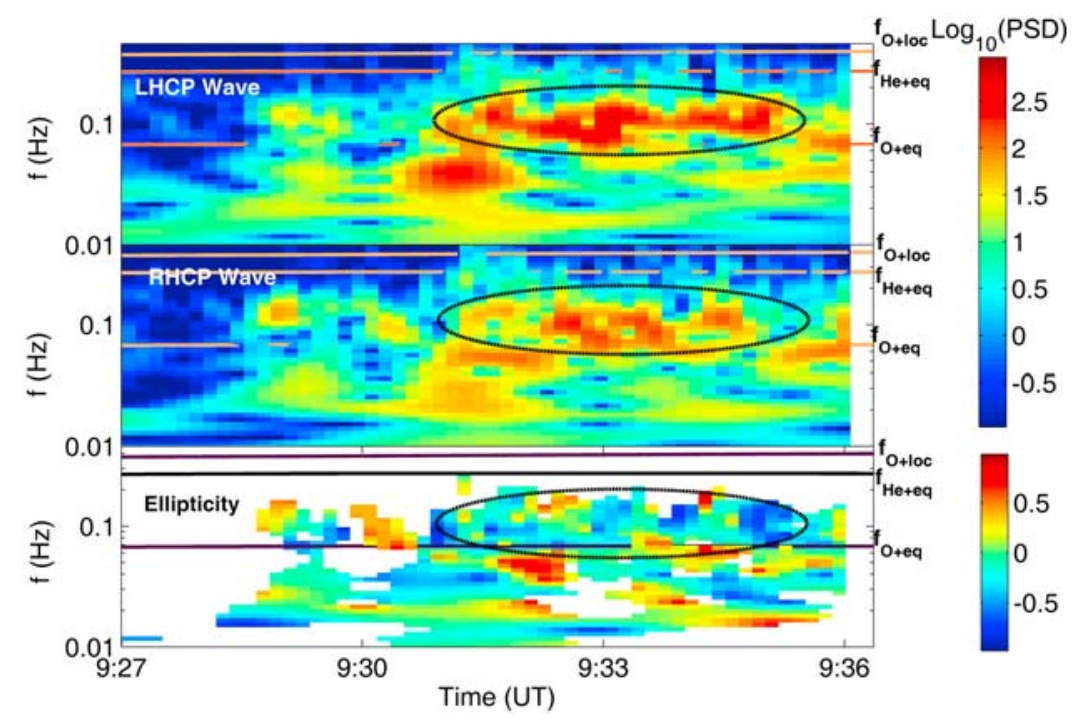

Figure 2. Wavelet power spectrum for the time interval of 09:27-09:36 UT selected from data of Figure 1. (top) Power spectrum of LHCP, (middle) RHCP components and (bottom) ellipticity of the transverse waves in the field-aligned coordinates are plotted. Dashed elliptical lines denote the enhanced EMIC waves.

[7] An overview of the Cluster SC3 data including the electron number density, the $\mathrm{H}^{+} \mathrm{He}^{+} \mathrm{O}^{+}$energy-time spectrogram in the particle energy flux units, the magnetic field in GSE coordinates, and power spectrum density during the time from 08:00 UT to 09:50 UT is shown in Figure 1. Figure 1a presents a plume crossed by the Cluster SC3 during the outbound plasmasphere pass on Sep. 4, 2005. Between 08:00 UT and 08:48 UT, Figure 1a presents a more dense plasma population, implying that the Cluster SC3 passed through the main plasmasphere. During the interval, as shown in Figures $1 \mathrm{~b}-1 \mathrm{~d}$, the increased ion fluxes observed by Cluster SC3 are just background due to penetrating particles from the outer radiation belt. Thereafter, Figure 1a presents that the electron density starts to increase at 08:52 UT, meaning that Cluster SC3 entered into the inner boundary of a plume. Since the high flux of ambient electrons in the plasmasphere brings the spacecraft potential to only a few volts positive relative to the plasma, spacecraft potential is a very good proxy of the total electron density [Pedersen et al., 2001]. The outer boundary of the plume is well identified with a sharp decrease of the spacecraft potential value shown in Figure 1e at 09:36 UT. We estimate the equatorially mapped locations of these two crossings of plume boundary, the inner density increase at $\sim 08: 52$ UT and the outer density decrease $\sim 09: 36$ UT, to be $L=5.67, \mathrm{MLT}=13.27$ and $L=7.53$ and $\mathrm{MLT}=13.72$, respectively. The extent of the plasmaspheric plume is about 1.86 in $L$-shell value, which meets the criterion mentioned above. These locations are consistent with the general shape of plasmaspheric plume structures in the afternoon sector. In the plasmaspheric plume, as shown in Figure 1b, the ring current is revealed by the presence of strong fluxes of highenergy $(>10 \mathrm{keV})$ trapped ions, typically observed by CODIF and identified as part of the ring current population [Vallat et al., 2004].

[8] In order to eliminate waves with frequencies above $10 \mathrm{~Hz}$, the high-resolution original data of the magnetic field have been averaged in the interval of $0.1 \mathrm{~s}$ so that the resampling frequency becomes $10 \mathrm{~Hz}$. Thereafter, the average magnetic field is calculated by a $25.6 \mathrm{~s}$ running average with the resampled magnetic fields data. Perturbation magnetic fields are calculated by subtracting average magnetic fields from resampled magnetic fields. The average magnetic field is considered as the ambient or static magnetic field at the place where the Cluster SC3 is located. As shown in Figures $1 \mathrm{f}$ and $1 \mathrm{~g}$, the amplitude of perturbation magnetic fields increases and reaches about $2.5 \mathrm{nT}$ in the outer boundary of the plasmaspheric plume, especially during the interval denoted by vertical dashed lines, i.e., from 09:30 UT to $09: 36$ UT. During the interval, as the strongest component of perturbation magnetic fields, $\Delta \mathrm{B}_{Z}$ is used to obtain the power spectrum density through Fast Fourier transforms (FFTs) with $25.6 \mathrm{~s}$ data intervals. As shown in Figure 1h, during two intervals denoted by vertical dashed lines, the pulsation frequencies of ULF waves lie in the vicinity of $0.1 \mathrm{~Hz}$

\section{Discussion and Conclusion}

[9] To better study characteristics of ULF waves observed by the Cluster SC3, it is necessary to transform perturbation magnetic fields in the GSE coordinates into those in the field-aligned coordinates, in which the two transverse components $\left(\mathrm{B}_{\mathrm{t} 1}\right.$ and $\left.\mathrm{B}_{\mathrm{t} 2}\right)$ are combined into left- and righthand polarized components $\left(\mathrm{B}_{\mathrm{r}}=\mathrm{B}_{\mathrm{t} 1}+i \mathrm{~B}_{\mathrm{t} 2}\right.$ and $\left.\mathrm{B}_{1}=\mathrm{B}_{\mathrm{t} 1}-i \mathrm{~B}_{\mathrm{t} 2}\right)$ [Volwerk et al., 2008]. In order to better present the wave power for lower frequency bands, a wavelet transform with Morlet mother wavelet [Mallat, 1998] is used to study the wave power for two polarized components $\left(B_{r}\right.$ and $\left.B_{1}\right)$. The Morlet wavelet is used as this wavelet can process complex data [Baumjohann et al., 1999]. Figure 2 presents the wavelet spectrograms for Cluster SC3 during the interval of 09:27-09:36 UT, corresponding to the interval denoted by dashed lines in Figure 1. Those local $\mathrm{O}^{+}$ion gyrofrequencies $\left(f_{\mathrm{O}+\text { Loc }}\right)$ are derived from the ambient magnetic field observed by the Cluster SC3 satellite. On the other 


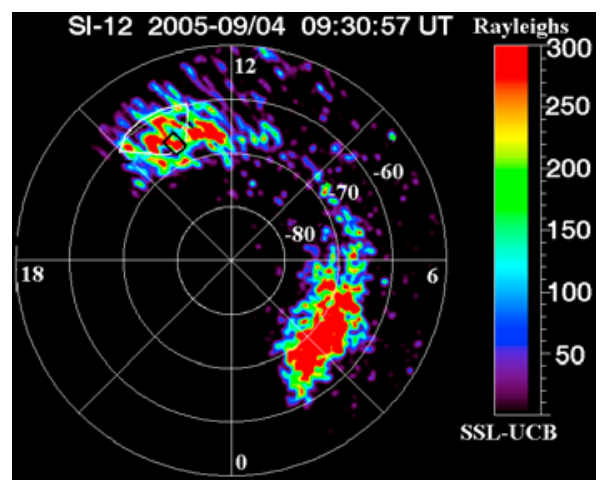

Figure 3. A proton aurora image from FUV SI12 instrument onboard the IMAGE spacecraft at 09:30:57 UT on September 4, 2005 mapped onto magnetic latitude and MLT coordinates. White fan-shaped line denotes a detached subauroral proton arc. Black rectangular line marks the footprint of SC3 satellite.

hand, those ion gyrofrequencies at the equatorial plane $\left(f_{\mathrm{O}+\mathrm{eq}}, \mathrm{f}_{\mathrm{He}+\mathrm{eq}}\right)$, which is the projection of Cluster trajectories along the magnetic field, can be calculated with the above mentioned model of magnetospheric magnetic fields.

[10] As shown in Figures 2 (top) and 2 (middle), the frequency band of ULF waves denoted by the dashed elliptical line lies below the local $\mathrm{O}^{+}$ion gyrofrequency $\left(f_{\mathrm{O}+\mathrm{Loc}}\right)$. To be noted, the band of ULF waves is between the $\mathrm{O}^{+}$ion gyrofrequency $\left(\mathrm{f}_{\mathrm{O}+\mathrm{eq}}\right)$ and the $\mathrm{He}^{+}$ion gyrofrequency $\left(f_{\mathrm{He}+\mathrm{eq}}\right)$ at the equatorial plane, in agreement with the theory of EMIC waves generated in the equatorial plane [Young et al., 1981]. The frequency band below the $\mathrm{f}_{\mathrm{He}+\mathrm{eq}}$ means that cold $\mathrm{He}^{+}$ions in the plasmaspheric plume have a strong influence on the generation of EMIC waves in the equatorial plane. As shown in Figure 2 (bottom), the ellipticity of the transverse waves (defined such that -1 denoted left hand circular polarization (LHCP), 0 linear polarization, and +1 denoted right hand circular polarization (RHCP)) demonstrate that most of the wave packets show linear-LH polarization, as expected for EMIC waves [Anderson et al., 1992b]. In addition, as shown in Figures 1a, 1b, and 1h, ULF waves occurred in the region of overlap between plasmaspheric plumes and ring currents. Therefore, observed ULF waves can be explained as EMIC waves generated in the equatorial plane, which is attributed to the EMIC instability caused by RC ions and enhanced by cold dense ions in plasmaspheric plumes.

[11] Since the SI12 channel of the IMAGE FUV instrument was designed to select the Doppler shifted Lyman $\mathrm{H}$-alpha line at $121.82 \mathrm{~nm}$ and to reject the non-Doppler shifted Lyman $\mathrm{H}$-alpha from the geocorona at $121.567 \mathrm{~nm}$ [Mende et al., 2000], the observed emissions mainly come from charge-exchanging precipitating protons. A proton aurora image from FUV SI12 instrument at 09:30:57 UT on September 4, 2005 (the time in the middle of the interval between 09:30 UT and 09:36 UT in Figure 2) is shown in Figure 3. A detached subauroral proton arc denoted by fan-shaped lines can be seen in the afternoon sector. To be noted, the footprint of Cluster SC3 denoted by the black rectangular line just lies in the subauroral proton arc. Therefore, it is reasonable that the subauroral proton arc is caused by the energetic ring current protons scattered into the loss cone under the RC-EMIC interaction in the plasmaspheric plume.

[12] In summary, based on the discussion of ULF waves observed by the Cluster satellite, we find that ULF waves occur in the plasmaspheric plume. The band of observed ULF waves is between the $\mathrm{He}^{+}$ion gyrofrequency and $\mathrm{O}^{+}$ ion gyrofrequency at the equatorial plane, implying that those ULF waves can be explained as EMIC waves generated by ring current ions in the equatorial plane and strongly affected by rich cold $\mathrm{He}^{+}$ions in plasmaspheric plumes. During the interval of observed EMIC waves, the footprint of Cluster SC3 lies in a subauroral proton arc with observations of the IMAGE FUV instrument, meaning that the subauroral proton arc is caused by energetic ring current protons scattered into the loss cone under the RC-EMIC interaction in the plasmaspheric plume. Therefore, the paper reveals the direct link between plasmaspheric plumes, EMIC waves and subauroral proton arcs.

[13] Acknowledgments. We thank the Cluster teams (FGM, WHISPER, EFW, CIS) and CAA for the high-quality data and successful operation. This research is supported by the National Natural Science Foundation of China (40604021, 40974088), the Keygrant Project of Chinese Ministry of Education (307019), and the Scientific Research Foundation for the Returned Overseas Chinese Scholars, State Education Ministry.

\section{References}

Anderson, B. J., and D. C. Hamilton (1993), Electromagnetic ion cyclotron waves stimulated by modest magnetospheric compression, J. Geophys. Res., 98, 11,369-11,382, doi:10.1029/93JA00605.

Anderson, B. J., R. E. Erlandson, and L. J. Zanetti (1992a), A statistical study of Pc 1-2 magnetic pulsations in the equatorial magnetosphere: 1. Equatorial occurrence distributions, J. Geophys. Res., 97, 30753088, doi:10.1029/91JA02706.

Anderson, B. J., R. E. Erlandson, and L. J. Zanetti (1992b), A statistical study of Pc 1-2 magnetic pulsations in the equatorial magnetosphere: 2. Wave properties, J. Geophys. Res., 97, 3089-3101, doi:10.1029/ 91JA02697.

Balogh, A., et al. (2001), The Cluster magnetic field investigation: Overview of in-flight performance and initial results, Ann. Geophys., 19, 1207-1217.

Baumjohann, W., R. A. Treumann, E. Georgescu, G. Haerendel, K.-H. Fornacon, and U. Auster (1999), Waveform and packet structure of lion roars, Ann. Geophys., 17, 1528-1534, doi:10.1007/s00585-999-1528-9.

Burch, J. L., et al. (2002), Interplanetary magnetic field control of afternoon-sector detached proton auroral arcs, J. Geophys. Res., 107(A9), 1251, doi:10.1029/2001JA007554.

Darrouzet, F., et al. (2006), Analysis of plasmaspheric plumes: CLUSTER and IMAGE observations, Ann. Geophys., 24, 1737-1756.

Darrouzet, F., J. De Keyser, P. M. E. Décréau, F. El Lemdani-Mazouz, and X. Vallières (2008), Statistical analysis of plasmaspheric plumes with Cluster/WHISPER observations, Ann. Geophys., 26, 2403-2417.

Darrouzet, F., J. De Keyser, and V. Pierrard (Eds.) (2009), The Earth's Plasmasphere: A CLUSTER and IMAGE Perspective, 296 pp., Springer, New York

Décréau, P. M. E., et al. (2001), Early results from the Whisper instrument on Cluster: An overview, Ann. Geophys., 19, 1241-1258.

Engebretson, M. J., et al. (2007), Cluster observation of Pc 1-2 waves and associated ion distributions during the October and November 2003 magnetic storms, Planet. Space Sci., 55, 829-848, doi:10.1016/j. pss.2006.03.015.

Erlandson, R. E., and A. Ukhorskiy (2001), Observations of electromagnetic ion cyclotron waves during geomagnetic storms: Wave occurrence and pitch angle scattering, J. Geophys. Res., 106, 3883-3895, doi:10.1029/ 2000JA000083.

Fraser, B. J., and T. S. Nguyen (2001), Is the plasmaspause a preferred source region of electromagnetic ion cyclotron waves in the magnetosphere?, J. Atmos. Terr. Phys., 63, 1225-1247, doi:10.1016/S13646826(00)00225-X.

Fraser, B. J., H. J. Singer, M. L. Adrian, D. L. Gallagher, and M. F. Thomsen (2005), The relationship between plasma density structure and EMIC waves at geosynchronous orbit, in Inner Magnetosphere Interactions: New Perspectives From Imaging, Geophys. Monogr. Ser., vol. 159, 
edited by J. L. Burch, M. Schulz, and H. Spence, pp. 55-68, AGU, Washington, D. C.

Fuselier, S. A., S. P. Gray, M. F. Thomsen, E. S. Claflin, B. Hubert, B. R. Sandel, and T. Immel (2004), Generation of transient dayside subauroral proton precipitation, J. Geophys. Res., 109, A12227, doi:10.1029/ 2004JA010393.

Gamayunov, K. V., and G. V. Khazanov (2008), Crucial role of ring current $\mathrm{H}+$ in electromagnetic ion cyclotron wave dispersion relation: Results from global simulations, J. Geophys. Res., 113, A11220, doi:10.1029/2008JA013494.

Gary, S. P., M. F. Thomsen, L. Yin, and D. Winske (1995), Electromagnetic proton cyclotron instability: Interactions with magnetospheric protons, J. Geophys. Res., 100, 21,961-21,972, doi:10.1029/95JA01403.

Gomberoff, L., and S. Cuperman (1982), Combined effect of cold $\mathrm{H}+$ and $\mathrm{He}+$ ions on the proton cyclotron electromagnetic instability, J. Geophys. Res., 87, 95-100, doi:10.1029/JA087iA01p00095.

Gustafsson, G., et al. (2001), First results of electric field and density observations by Cluster EFW based on initial months of operation, Ann. Geophys., 19, 1219-1240.

Horne, R. B., and R. M. Thorne (1993), On the preferred source location for the convective amplification of ion cyclotron waves, J. Geophys. Res., 98, 9233, doi:10.1029/92JA02972.

Immel, T. J., S. B. Mende, H. U. Frey, L. M. Peticolas, C. W. Carlson, J.-C. Gérard, B. Hubert, S. A. Fuselier, and J. L. Burch (2002), Precipitation of auroral protons in detached arc, Geophys. Res. Lett., 29(11), 1519, doi:10.1029/2001GL013847.

Jordanova, V. K., M. Spasojević, and M. F. Thomsen (2007), Modeling the electromagnetic ion cyclotron wave-induced information of detached subauroral proton arcs, J. Geophys. Res., 112, A08209, doi:10.1029/ 2006JA012215.

Kozyra, J. U., T. E. Cravens, A. F. Nagy, and E. G. Fontheim (1984), Effects of energetic heavy ions on electromagnetic ion cyclotron wave generation in the plasmapause region, J. Geophys. Res., 89, $2217-$ 2233, doi:10.1029/JA089iA04p02217.

Mallat, S. A. (1998), Wavelet Tour of Signal Processing, Academic, San Diego, Calif.

Masson, A., et al. (2009), Advances in plasmaspheric wave research with CLUSTER and IMAGE observations, Space Sci. Rev., 145, 137-191, doi:10.1007/s11214-009-9508-7.

McIlwain, C. E. (1961), Coordinates for mapping the distribution of magnetically trapped particles, J. Geophys. Res., 66, 3681-3691, doi:10.1029/JZ066i011p03681.

Mende, S. B., et al. (2000), Far ultraviolet imaging from the IMAGE spacecraft. 3. Spectral imaging of Lyman-a and OI $135.6 \mathrm{~nm}$, Space Sci. Rev., 91, 287, doi:10.1023/A:1005292301251.

Miyoshi, Y., K. Sakaguchi, K. Shiokawa, D. Evans, J. Albert, M. Connors, and V. Jordanova (2008), Precipitation of radiation belt electrons by EMIC waves, observed from ground and space, Geophys. Res. Lett., 35, L23101, doi:10.1029/2008GL035727.

Pedersen, A., P. Décréau, C.-P. Escoubet, G. Gustafsson, H. Laakso, P.-A. Lindqvist, B. Lybekk, A. Masson, F. Mozer, and A. Vaivads (2001),
Four-point high time resolution information on electron densities by the electric field experiments (EFW) on Cluster, Ann. Geophys., 19, 1483-1489.

Rème, H., et al. (2001), First multispacecraft ion measurements in and near the Earth's magnetosphere with the identical CLUSTER Ion Spectrometry (CIS) experiment, Ann. Geophys., 19, 1303-1354.

Sakaguchi, K., K. Shiokawa, Y. Miyoshi, Y. Otsuka, T. Ogawa, K. Asamura, and M. Connors (2008), Simultaneous appearance of isolated auroral arcs and Pc1 geomagnetic pulsations at subauroral latitudes, J. Geophys. Res., 113, A05201, doi:10.1029/2007JA012888.

Sibeck, D. G., R. W. Mcentire, A. T. Y. Lui, R. E. Lopez, and S. M. Krimigis (1987), Magnetic field drift shell splitting: Cause of unusual dayside particle pitch angle distributions during storms and substorms, J. Geophys. Res., 92, 13,485-13,497, doi:10.1029/JA092iA12p13485.

Spasojević, M., H. U. Frey, M. F. Thomsen, S. A. Fuselier, S. P. Gary, B. R. Sandel, and U. S. Inan (2004), The link between a detached subauroral proton arc and a plasmaspheric plume, Geophys. Res. Lett., 31, L04803, doi:10.1029/2003GL018389.

Tsyganenko, N. A., and M. I. Sitnov (2005), Modeling the dynamics of the inner magnetosphere during strong geomagnetic storms, J. Geophys. Res., 110, A03208, doi:10.1029/2004JA010798.

Vallat, C., et al. (2004), First comparisons of local ion measurements in the inner magnetosphere with ENA magnetospheric image inversions: Cluster-CIS and IMAGE-HENA observations, J. Geophys. Res., 109, A04213, doi:10.1029/2003JA010224.

Volwerk, M., R. Nakamura, W. Baumjohann, T. Uozumi, K. Yumoto, and A. Balogh (2008), Tailward propagation of Pi2 waves in the Earth's magnetotail lobe, Ann. Geophys., 26, 4023-4030.

Williams, D. J. (1987), Ring current and radiations belts, Rev. Geophys., 25, 570-578, doi:10.1029/RG025i003p00570.

Yahnina, T. A., H. U. Frey, T. Bosinger, and A. G. Yahnin (2008), Evidence for subauroral proton flashes on the dayside as the result of the ion cyclotron interaction, J. Geophys. Res., 113, A07209, doi:10.1029/2008JA013099.

Young, D. T., et al. (1981), Wave-particle interactions near observed on GEOS 1 and 2: 1. Propagation of ion cyclotron waves in $\mathrm{He}+$ rich plasma, J. Geophys. Res., 86, 6755-6772, doi:10.1029/JA086iA08p06755.

P. M. E. Décréau and J. G. Trotignon, Laboratoire de Physique et Chimie de l'Environnement, University of Orléans, CNRS, 3A Avenue de la Recherche Scientifique, F-45071 Orléans CEDEX 2, France.

X. Deng, X. Lin, Y. Pang, J. Wang, Z. Yuan, and M. Zhou, School of Electronic Information, Wuhan University, Wuhan, Hubei 430079, China. (y_zgang@vip.163.com)

H. U. Frey, Space Sciences Laboratory, University of California, 7 Gauss Way, Berkeley, CA 94720-7450, USA.

E. Lucek, Blackett Laboratory, Imperial College London, Prince Consort Road, London SW7 2BW, UK. 